\title{
Financial Literacy, Stability, and Security as Understood by Male Saudi University Students
}

\author{
Amani K. Hamdan Alghamdi ${ }^{1}$, Sue L. T. McGregor ${ }^{2}$ \& Wai Si El-Hassan ${ }^{3}$ \\ ${ }^{1}$ Imam Abdulrahman Bin Faisal University, Dammam, Saudi Arabia \\ ${ }^{2}$ Professor Emerita, Principal Consultant, McGregor Consulting Group, Seabright, Nova Scotia, Canada \\ ${ }^{3}$ Guildford College of Further and Higher Education, Surrey, England \\ Correspondence: Amani K. Hamdan Alghamdi, College of Education, Imam Abdulrahman Bin Faisal University, \\ PO Box 1982, Dammam 31441, Saudi Arabia. Tel: 966-553-332-700. E-mail: akhalghamdi@iau.edu.sa
}

Received: April 8, 2021

doi:10.5539/ijef.v13n7p7
Accepted: May 19, 2021

Online Published: June 5, 2021

URL: https://doi.org/10.5539/ijef.v13n7p7

\begin{abstract}
This paper recounts an inaugural study of male Saudi university students' understandings of financial literacy, financial stability, and financial security and how they plan to achieve these. Using convenience sampling, 79 male respondents (53\% response rate) from an Eastern Province university completed a six-question open-ended email instrument. Data collected in November 2020 were analyzed using descriptive statistics. Results showed that while their understanding of what constitutes financial literacy was solid enough (with some gaps), their notion of how to ensure financial stability and security was in question. They made no mention of retirement, taxation, or estate planning and limited insurance to medical. Despite self-rating themselves as having good $(47 \%)$ or average (32\%) financial literacy, results suggest an imbalanced personal financial system, which bodes ill for future financial resilience, stability, and security. Respondents placed an inordinate weight on the risky ventures of investing (79\%) and entrepreneurship (49\%) to make a living and to use for retirement while concurrently not valuing goal setting, budgeting, or funding emergencies. Virtually all (99\%) respondents said they planned to learn more about financial literacy, and they tendered an array of ideas for how the university could make this happen.
\end{abstract}

Keywords: financial literacy, financial stability, financial security, male university students, Saudi Arabia, Vision 2030

\section{Introduction}

\subsection{Overview of Problem}

"Financial literacy is internationally recognized as an essential requirement for citizens who need to make informed personal finance decisions in an increasingly ... complex financial system" (Douissa, 2020, p. 1). On the international scene, there is a bourgeoning interest in financial literacy in the Middle East (Lyons \& Kass-Hanna, 2019) with Saudi Arabia no exception. In its recent national development plan (Vision 2030), the Saudi government has committed to a thriving economy that is less dependent on oil and more dependent on knowledge (Kingdom of Saudi Arabia [KSA], 2016). As with other governments (Douissa, 2020), Saudi leaders have committed to designing "an education [system] that contributes to economic growth [via] a modern curriculum focused on rigorous standards in literacy, numeracy" (KSA, 2016, p. 40).

The argument underpinning the study herein is that, given the intent of Vision 2030, the Saudi education system must especially concern financial literacy. In recent years, "the connection between the levels of literacy a country achieves and its level of economic development has become increasingly important" (Emaikwu, 2011, p. 144). A citizenry that is financially literate will be better able to contribute to a healthy and thriving economy (Douissa, 2020; Western et al., 2012). In that spirit, the Saudi government aimed for a 34\% financial literacy rate by 2020 (KSA, 2020), but this rate still falls far below other world nations (King Khalid Foundation [KKF], 2018). Regrettably, financial literacy is still an under-researched phenomenon in Saudi Arabia, but interest is growing (Alghamdi \& El-Hassan, 2020).

A decade ago, research showed that $90 \%$ of Saudi youth were interested in increasing their financial knowledge and becoming more financially literate (Fareed, 2012). Despite this earlier interest, a World Bank 2017 survey 
estimated that less than one third $(31 \%)$ of Saudi adult citizens were financially literate, the lowest rate in the Gulf region (KKF, 2018; KSA, 2020). In 2018, Saudi citizens were borrowing at very high rates with one in five defaulting on loan payments. Nearly half (43\%) had experienced an income drop (before the COVID-19 pandemic), and one quarter were unable to pay utility bills. Almost half (45\%) had no savings, and $80 \%$ had no investment plans (KKF, 2018; "Why financial education," 2019).

From a research perspective, a confounding factor is that, in Saudi's gender-segregated society, most academic studies are focused on either males or females. In two exceptions, Mian (2014) reported that Saudi males and older citizens were more financially literate than Saudi females and younger citizens with no significant impact from education or employment status. Attia and Engelhardt (2016) reported instead that Saudi men and women were on par in terms of being financially literate, and age did not factor in at all. Respondents scored highest in basic money management followed closely by financial planning and to a lesser extent investment. Saudi scores were on par for the Middle East in general but low compared to other nations (Attia \& Engelhardt, 2016). There is no consensus yet about degree of financial literacy.

Furthermore, earlier studies have not focused on university students who are the immediate work force contributing to achieving Vision 2030. Again, as an exception, Albassami and Alyousif (2019) discerned that Saudi consumers (one third were university age) scored below the minimum required level for successful financial behavior and management that leads to financial stability and security. Most (91\%) respondents in Alghamdi and El-Hassan's (2020) inaugural KSA financial literacy study were female university students who scored low on essential financial concepts such as financial calculations and record keeping, incomes sources, take-home pay, and insurance. They scored very low (below 40\%) on questions pertaining to retirement (i.e., financial security).

The study herein thus focused on male Saudi university students' understanding of financial literacy and financial security balancing Alghamdi and El-Hassan's (2020) focus on Saudi university women. This study also augments their focus on financial literacy with the additional notions of financial stability and financial security. These three constructs are related but different (to be discussed). A concern for financial stability and financial security ties in well with Vision 2030's goals wherein the KSA government is partially depending on citizens' financial acume for achievement of its national development plan ("His Excellency," 2019; KSA, 2016). After the literature review section, the research question is articulated, and the method is described followed with the presentation and discussion of results (and limitations) wrapping up with concluding comments.

\subsection{Literature Review}

\subsubsection{Saudi Financial Literacy Context}

The Saudi Ministry of Education (MOE), which is responsible for primary and secondary schools, is involved in initiatives focused on "spreading the culture of financial literacy" (Saudi Gazette Report, 2020, para. 6). This messaging matters because secondary students are potential university students. The latter should be concerned with financial literacy, stability, and security, because their financial prowess translates into contributions to or drains on the Saudi economy. Personal and household economic security is linked to national economic prosperity and vice versa (Western et al., 2012).

The Saudi Arabian Monetary Authority (SAMA) is also committed to "promoting financial literacy and awareness among different segments in society and especially the youth" (KKF, 2018, p. 26). In 2017, the SAMA launched an executive program to promote the Saudi financial sector's efforts to encourage savings, financing, investing, and financial planning among its citizens. Embedded within this program is a Financial Literacy Entity (FLE) (KKF, 2018; KSA, 2020). The FLE will "coordinate and synchronize efforts revolving around financial education to ensure quality and consistency of materials and messages, as well as reach and scale" (KSA, 2020, p. 38) and "improve awareness of the benefits of financial planning" (KSA, 2020, p. 60).

In the higher education sector, King Abdulaziz University (KAU), the highest ranked university in the Arab region, recently began to focus on improving its students' financial literacy. Three years ago, KAU held a workshop entitled Promoting a culture of savings in the Kingdom according to the 2030 vision and its financial, social impact ("His Excellency," 2019). Under the aegis of the Institute of Islamic Economics (IIE), workshop participants explored the university's role in achieving Vision 2030. The KAU's financial clinic is an important, related initiative. It is a "mechanism of action in promoting the culture of financial dealings in societies, through financial planning that sets specific goals at the level of the individual and the family... to help community members assume their responsibility for achieving the vision" ("His Excellency," 2019, para. 6).

Generally speaking, youth tend to have a poor understanding of how to plan for a financially secure future 
(Lusardi et al., 2010; Nidar \& Bestari, 2012). By age association, university students may also encounter limited notions of financial stability that can be hampered by reduced financial literacy. This eventuality is a concern in Saudi Arabia, where "consumers are increasingly expected to play a more active role in becoming financially capable to make suitable personal financial decisions for the sake of their future financial wellbeing" (Albassami \& Alyousif, 2019, p. 2). This sentiment echoes the tenets of "securing financial stability" (Albassami \& Alyousif, 2019 , p. 2), which is inherently tied to financial capability and literacy.

Respecting the dearth of research in Saudi Arabia about financial literacy, the authors recognized an opportunity to distinguish it from financial stability and financial security. This conceptual clarification should smooth future dialogue around this phenomenon in the Saudi economic and educational contexts vis-à-vis Vision 2030's focus on supporting both a thriving economy and an education system with a keen focus on literacy and numeracy (KSA, 2016). This conceptual clarification should also contribute to generating meaningful results for other nations (Middle East and otherwise) that are newly concerned with financial literacy. The inaugural linking of these three constructs in such detail is a significant contribution to the financial literacy knowledge base.

\subsubsection{Financial Literacy}

Financial literacy is "being educated about money and finance, with a special focus on an individual's [everyday] personal finances [and issues]. Being financially literate enables people to make smarter money management decisions that lead directly to a financially secure future" (O'Connel, 2019, p. 7). The intent is to ensure individual financial well-being (Organization for Economic Cooperation and Development [OECD], 2012).

Financially literate people can efficiently manage their personal financial matters and make appropriate decisions about many facets of their finances: earnings and income, budgeting expenses and planning, insurance, credit and debt, real estate (mortgages, rental agreements), taxes, savings and investments, retirement, and wills and estate planning. By association, they can proficiently apply key financial concepts and principles such as planning, prioritizing, goal setting, managing, and risk aversion (Kenton, 2019; O'Connel, 2019; US Department of the Treasury, 2008). Relative to other financial literacy constructs, goal setting and budgeting are considered the most powerful and impactful tools for controlling spending to allow for saving and investing (Penn State University, 2021).

Financial literacy is "a combination of awareness, knowledge, skill, attitude, [values,] and behaviour necessary to make sound financial decisions and ultimately achieve individual financial well-being" (Atkinson \& Messy, 2012, p. 14). Financial literacy is both objective and subjective. It thus includes, respectively, (a) internalizing financial information, skills, and behaviour as new knowledge and (b) verifying, stimulating, and challenging "values, beliefs, attitudes, expectations and motivations about money" (Danes et al., 2013, p. 23; see also OECD, 2019). Of relevance to this paper is that financial literacy contributes to financial stability (McGregor, 2020; Singh, 2014). Financially literate people "can manage internal and external challenges to their finances" (McGregor, 2020, p. 56) so they can consistently experience financial stability and financial security.

\subsubsection{Financial Stability}

Finance is Old French finer, 'an ending, payment, to settle a debt' (Harper, 2021). In practice, finance refers to acquiring funds and managing money and investments (Anderson, 2014). Stable is Latin stabilis, 'steadfast, constant, unwavering' (Harper, 2021). If something is stable, it will not easily overturn, collapse, or give way. It is consistent and dependable because it is balanced, resistant to changes in position or condition, and not easily disturbed (Anderson, 2014). Stable finances are key to personal economic security.

To that end, households and individuals tend to have a financial system comprising many interrelated parts (e.g., insurance, credit, taxes) that is managed through financial planning. Allen and Wood (2006) proposed that "stability is regarded as a property of a system, and not as a state of affairs that might or might not be prevailing at a particular time" (p. 154). Financial systems thus have degrees of stability. Indeed, financial stability operates along a continuum (Schinasi, 2004) (Latin continuus, 'uninterrupted,' Harper, 2021).

From a continuum perspective "maintaining financial stability does not necessarily require that each part of the financial system operate persistently at peak performance" (Schinasi, 2004, p. 7). Allen and Wood (2006) concurred, positing that financial systems will react differently to perturbations of different types and sizes. Indeed, disturbances can be expected and may even be welcomed and healthy, because disruptions in individual parts of the financial system can serve to strengthen it in the long term as it adapts and gains resiliency (Schinasi, 2004). To that end, "financial stability entails both preventive and remedial dimensions" (Schinasi, 2004, p. 7).

Prevention and remediation serve to ensure that one's financial system can deal with imbalances before they become a threat to equilibrium. Financial stability is not a static condition; it is fluid, changes over time and 
circumstances, and looks different at different junctures in time. Schinasi (2004) described a "financial system [as] being in a perpetual state of flux and transformation while its ability to perform its key functions remains well within a set of tolerable boundaries" (p. 8). Stable finances will not immediately degenerate into instability when they encounter disturbances (Allen \& Wood, 2006). But, when people notice aspects of their finances approaching these boundaries, they can assume their financial system is losing some of its ability to perform optimally (Allen \& Wood, 2006; Schinasi, 2004) (e.g., debt load may be excessive relative to available debt-servicing income).

Indeed, some financial systems may appear to be stable and holding their own, but when the system encounters a shock, it falters badly and is placed at risk (Allen \& Wood, 2006). An example would be a household that is treading water - paying bills as they come due but struggling when there is major hit to the budget (e.g., car repair or doctor's bill). Their financial system fails them, because it only appeared stable; it was, in effect, an unstable system lacking balance and built-in support (Allen \& Wood, 2006).

The stability of one's finances can be threatened by both cumulative mini shocks (incremental build up of imbalances) and abrupt external shocks (significant and unanticipated events) (Schinasi, 2004). Financially stable households will be able to dampen the impact of these shocks rather than experience their amplification (Allen \& Wood, 2006). People must thus be prepared to keep their financial system running so that aspects of their finances can perform in their best interest. People's (a) ability to tolerate financial risk (i.e., lose money), (b) their future-time orientation and (c) their self-worth impact financial stability (Husiyah \& Fazilah, 2011).

For clarification, future-time orientation pertains to how much a person pays attention to the future when making financial decisions today. Do they have a financial plan? Are they aware of their needs into the future? Have they set goals with those needs in mind? (Lee et al., 2017). Self-worth concerns a sense of one's own value as a human being and is tied to understanding and accepting oneself (Husiyah \& Fazilah, 2011; "Self-worth," n.d.). Financial planning variables also influence a household's financial stability. Examples of such variables include indebtedness; debt servicing (i.e., principle, interest payments, and penalties); degree of insolvency; disposable income; income sources; employment status and type; assets (wealth); and savings vehicles. These variables are impacted by sex, age, and other demographic and life cycle factors (Kask, 2003).

The fluidity and flux state of their financial stability requires people to accept three key principles. They must view their financial situation as (a) risky and (b) grounded in uncertainty that is (c) mitigated by trust in humans and other institutions that can impinge on a person's financial stability (e.g., labour markets, financial institutions, policy regimes, stock markets). Ironically, trust is a leap of faith and fragile at the best of times making financial stability both a game of chance and a calculated choice (Schinasi, 2004). That said, financial stability leads to financial resilience and financial security in that people can weather unforeseen life events, financial stressors, and shocks (Duncan \& Lo, 2018; Kagan, 2017; Mistry et al., 2004).

\subsubsection{Financial Security}

Secure is Latin secures, 'without care, free from danger' (Harper, 2021). Security pertains to the certainty of remaining safe, sheltered and protected from exposure to threats, shocks, or attacks (Anderson, 2014). Securing their financial future means safeguarding and fortifying it from harm and loss (Cautero, 2019). Although most people set financial security as a long-term financial goal, it can mean different things to different people at different times in their lives. For some people, finances are secure if they have accumulated material possessions. Others link it to being able to sustain a particular standard of living and lifestyle. Still others feel secure financially if they can live in the present and save for the future. A lack of security can cause distress and worry and make people lose confidence in their ability to effaciously plan (Cautero, 2019; Howell et al., 2012).

Financial security is objective (cognitive - what people know). But it is also a subjective perception that, should financial circumstances change in the future, one will be able to meet basic needs, afford intended purchases, contribute to planned goals, and still have a cushion. This security is affected by income (flow of money), savings and wealth (stockpile of money), and debt obligations (jammed-up money). People are financially secure when they are not worried about achieving financial goals in their myriad forms (Cautero, 2019; Howell et al., 2012).

\subsection{Research Problem and Question}

Saudi Arabia faces a dilemma. Its new national development plan (Vision 2030) is focused on shifting from an oil to a knowledge-based economy via education that fosters literacy and numeracy (KSA, 2016). This transition is happening in conjunction with underdeveloped research on citizens' financial literacy levels, including university students (Albassami \& Alyousif, 2019; Alghamadi \& El-Hassan, 2020), and how lack of financial 
literacy might affect achieving Vision 2030's thriving economy. University students are the nation's future work force. Their ability to be literate about their finances so they can ensure a secure and stable financial future is key to Saudi's planned shift to its economy (KSA, 2016). Their personal financial stability and security are inherently tied to the nation's economic prosperity and vice versa ("His Excellency," 2019; Western et al., 2012). One research question thus guided this study: "What are male Saudi university students' understandings of financial literacy and stability, and do they plan to achieve financial literacy and how?" This is the first time that this perspective has been brought to the Saudi financial literacy knowledge base and the first time financial literacy has been bound to financial stability and financial security in this context as it informs national development.

\section{Method}

An exploratory, descriptive, cross-sectional research design involved using open-ended questions to collect qualitative data (words) that were converted to and reported as quantitative data (numbers). Exploratory research uncovers insights into a phenomenon leading to greater understandings that lay the groundwork for more comprehensive studies. Descriptive research describes what exists as well as its frequencies and then categorizes information (McGregor, 2018). In this case, the intent was to address the dearth of data about Saudi male university students' levels of financial literacy as they graduate to become productive members of Saudi's national economy.

\subsection{Sample Frame}

Inspired by Alghamdi and El-Hassan's (2020) inaugural financial literacy study with mainly Saudi female university students, convenience sampling involved drawing on male students attending a university in Saudi's Eastern Province (one of 13 provinces). The lead author had responded to interest from the College of Economics and Administration's Department Head. He was familiar with Alghamdi and El-Hassan's (2020) study and observed that the 150 male students in the college were specialized in (or learning about) financial stability and security. The lead author accepted his invitation to conduct research with these students. The final sample frame comprised $\mathrm{N}=79$ male students; demographic information was unavailable at the time.

\subsection{Instrument Development and Data Collection}

Six sub-questions were developed to collect relevant data to address the research question. First, respondents were asked to list at least three things they needed to know about to ensure their financial security. Question two (a 5-point Likert scale) asked them to self-rate their own financial literacy ranging from very little (1) to excellent (5). The remaining open-ended questions queried: (3) What will be your main financial resources after graduation? (4) What will you do with the money you make/earn before retirement? (5) What financial support/resources do you think you will need upon retirement? and (6) Are you planning to learn more about financial literacy? Please suggest ways the university can help.

Data were collected in November 2020. The College's administrative staff emailed the instrument to all enrolled students (150) with directions to type responses directly into the Word document and return to sender by email within two weeks. Instrument completion constituted consent (Lindermann, 2019; Marra \& Bogue, 2006; Ramshaw, 2016). The majority (91\%) responded in Arabic instead of English. The College's administrative staff forwarded all returned instruments to the lead author. The final sample frame comprised $\mathrm{N}=79$ male students representing a 53\% response rate, which exceeds the 33-40\% average for an internal email delivery system (Lindermann, 2019; Ramshaw, 2016) and was encouraging in the midst of a global pandemic. Anonymity was assured.

\subsection{Data Analysis}

Upon receipt, the Arabic data were translated to English, and then all English data were recorded in an Excel workbook prior to analysis. Quantitative data (Likert scale) were analyzed using descriptive statistics (frequencies, percentages). After counting and organizing the open-ended questions' qualitative data, the resultant quantitative results were also analyzed using descriptive statistics (frequencies, percentages). This rudimentary analysis is acceptable with exploratory, descriptive research, which strives to describe a phenomenon rather than seek associations (correlations) or causation (McGregor, 2018).

\section{Results}

Overall (per the main research question), respondents (Saudi male university students) saw value in financial literacy and financial stability and were able to share their views on how to make this happen. In their opinion, financial security and stability depend especially on savings, investments, and being able to budget and manage their money. They placed little value on such financial strategies as setting financial goals or having an 
emergency fund, which are considered the crux of any financial plan. Despite this, they rated their level of financial literacy as good $(47 \%)$ or average $(32 \%)$. Virtually all $(99 \%)$ respondents said they planned to learn more about financial literacy, and they readily tendered a wide array of ideas for how the university could help make this happen.

Virtually all (97\%) respondents believed that their salaries would be the main source of income while working. Nearly half (48\%) identified investment-generated income (dividends and interest) as a key source of earnings. Nearly all (75\%) intended to use their earned income to invest in the stock market. About half (49\%) saw themselves using their earnings to buy real estate for rental income or to start income-earning commercial activities. Fewer mentioned paying basic expenses, saving, or owning a house. Three key sources of retirement income were envisioned (63\% each): investment dividends, pensions, and self-employment. Detailed results are now presented organized by the six sub-questions.

\subsection{Question 1: Ensuring Financial Security}

On average, each respondent tendered three to four financial strategies they must know about to achieve financial security. Figure 1 profiles the top-12 answers by frequency. The most identified financial strategies were saving and investing (40-50\%) followed to a lesser extent by budgeting and managing/cutting down on expenses (20-30\%). The remaining seven strategies were noted less than $20 \%$ of the time and dealt with income sources (fixed or diversified), debt management/loan avoidance, having an emergency fund, and setting financial goals. To an even lesser extent were other strategies (not in Figure 1): (a) understand the current (tough) economic situation, (b) know about their current financial position, (c) consult with financial advisors, (d) secure part-time as well as full-time employment and (e) understand financial security as a concept and how to achieve it.

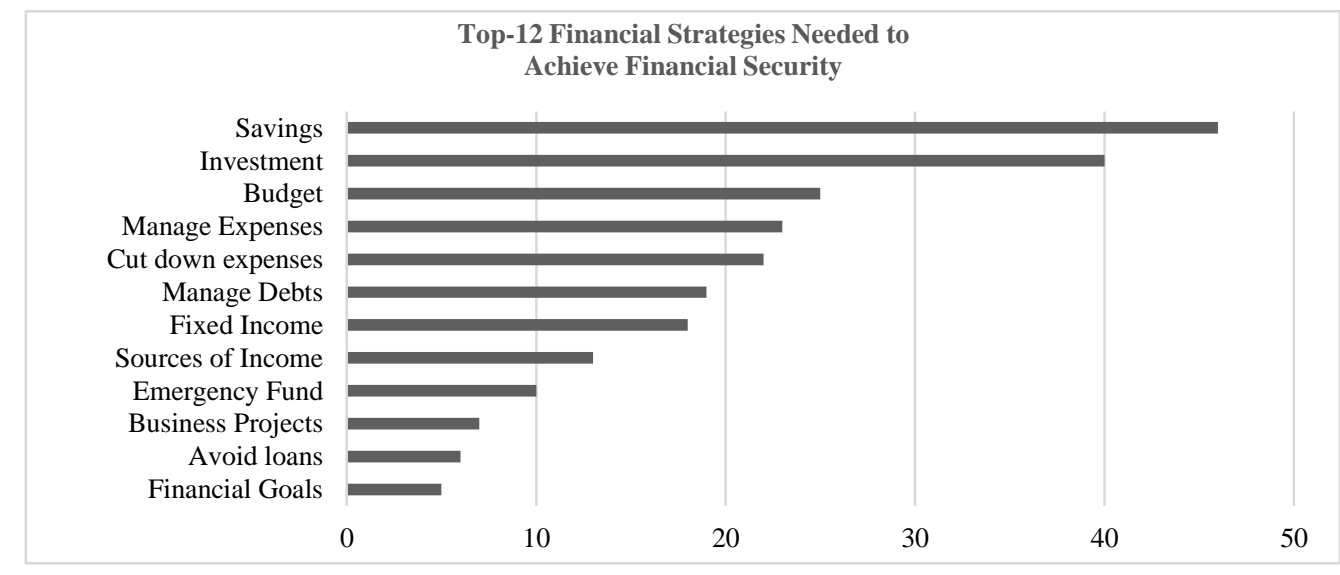

Figure 1. Top-12 financial strategies needed to achieve financial security (does not total 100)

\subsection{Question 2: Self-Rating of Financial Literacy}

With Alghamdi and El-Hassan's (2020) results for Saudi university students' financial literacy as a backdrop, respondents' perception of their own level of financial literacy was solicited. Most respondents self-rated their financial literacy as good $(47 \%, \mathrm{n}=37)$ or average $(32 \%, \mathrm{n}=25)$. One in ten respondents rated their financial literacy as excellent $(10 \%)$ or very little to none (11\%) (see Figure 2 ).

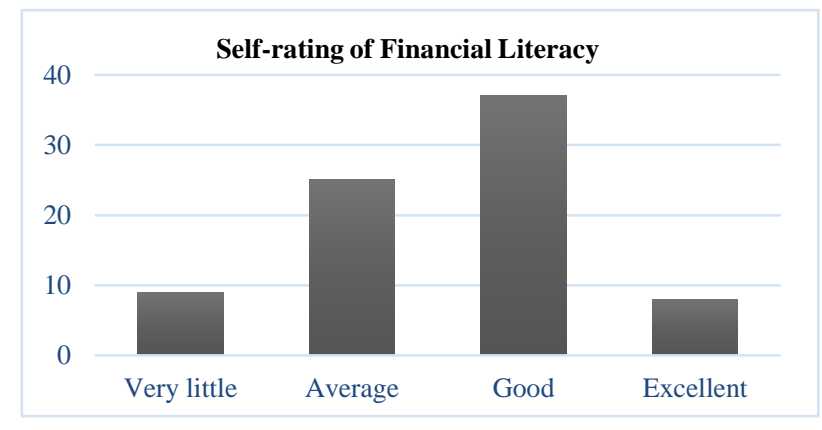

Figure 2. Self-rating of financial literacy 


\subsection{Question 3: Financial Resources After Graduation}

This question queried how Saudi male university students would secure finances after graduation. Figure 3 illustrates their main responses (frequencies). Virtually all $(97.5 \%, \mathrm{n}=77)$ respondents indicated salaries as their main source of income. A few mentioned seeking a government position or working for Aramco (a Saudi public petroleum and natural gas company, which was deemed as a stable job that guaranteed a fixed source of income). Nearly half $(48 \%, \mathrm{n}=38)$ thought that financial returns could be obtained from investing in the stock market, mutual funds, Islamic funds, or digital currencies. One respondent mentioned high-yielding, high-risk investments.

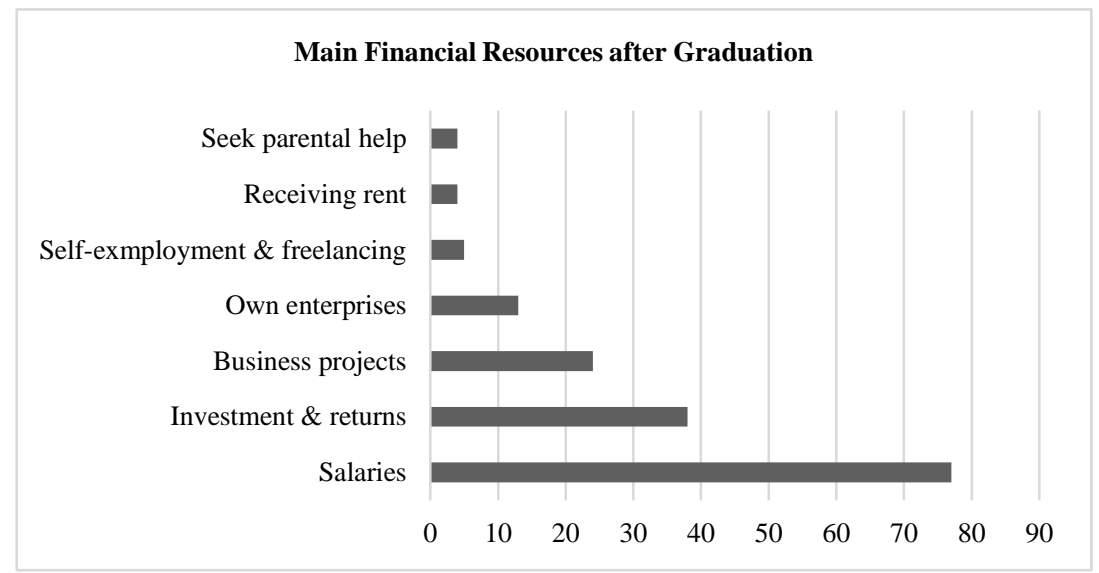

Figure 3. Main financial resources after graduation ( $\mathrm{N}=79$, totals more than 100)

Almost one-third $(30 \%, \mathrm{n}=24)$ said they would involve themselves in business projects (e.g., online commercial projects, mobile shops, automated car washes, or transport and delivery mobile apps). Sixteen percent (16\%, $\mathrm{n}=13$ ) said they would create their own enterprise. To a lesser extent (approximately 6\% each), respondents said they would seek self-employment and freelancing, receive rent from their properties, and seek temporary financial help from their parents (see Figure 3). One respondent said he would depend on a family inheritance. A smaller group of participants $(15 \%, \mathrm{n}=12$, not in Figure 3) mentioned getting part-time work (e.g., Uber), obtaining a business start-up loan, drawing an annual income from their parent's family business, drawing on savings, using remaining scholarship money, and trading in real estate, gold or currency exchange.

\subsection{Spending Money Earned Before Retirement}

Respondents were asked what they intended to spend their money on before their active work life was over and they had retired (behaviour that affects how much is available to save for retirement). Three-quarters $(75 \%, \mathrm{n}=59)$ said they would spend their money on investments in hope of earning more money and gaining wealth (see Figure 4). Among them in particular, nearly half $(47 \%)$ said they would invest in something novel like digital currencies with $14 \%$ intending to invest in conventional stocks. Very few respondents said they would invest in themselves and their families, business projects or partnerships, other business and commercial projects, or long-term and low-risk investments (e.g., bonds).

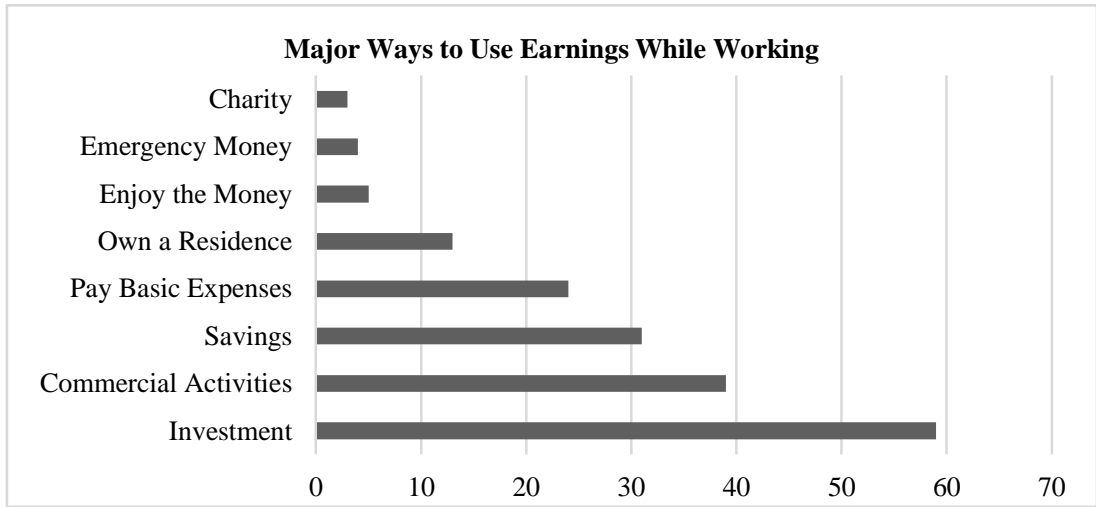

Figure 4. Major ways to use earnings while working ( $N=79$, frequencies total more than 100) 
About half $(49 \%, n=39)$ of the respondents said they would involve themselves with commercial activities. Among this group, one-third intended to build and secure their own real estate (e.g., buildings and land) to generate rental income. Nearly $40 \%$ wanted to run their own commercial projects, and $13 \%$ would start and run their own business. Two respondents intended to expand their existing business enterprise. A few respondents intended to trade in the stock market or real estate or run a guaranteed project (see Figure 4).

About one third $(n=31)$ of respondents intended to save their money. One quarter said they would pay basic, fixed expenses such as housing, food, clothing, and family obligations. Sixteen percent $(n=13)$ envisioned building or owning their own home. A very small number of respondents (approximately 5\%) said they would (a) enjoy their money after they payed basic expenses and saved some of it, (b) put some aside for emergencies, (c) donate to charity or (d) fund an endowment (e.g., building mosques) (see Figure 4). To an even lesser extent (not in Figure 4), some respondents said they would get married, start a family, buy a car, help their parents, pay off debts, set up a retirement fund, or carry on working in their own business. One respondent said he intended to spend nearly all (70\%) of what he earned.

\subsection{Question 5: Financing Retirement}

This question sought insights into what financial resources or support respondents thought they would need to achieve financial stability in retirement. Figure 5 profiles their thoughts on financing a secure retirement.

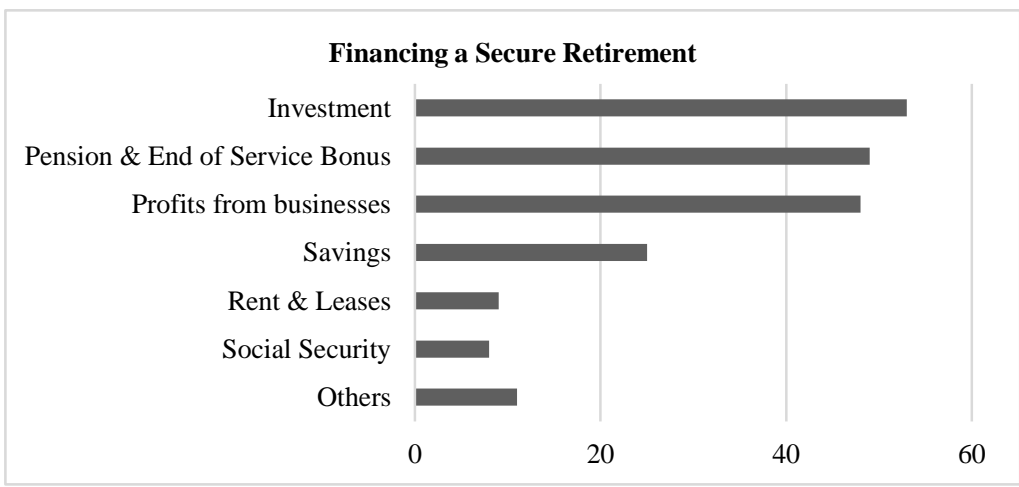

Figure 5. Financing a secure retirement $(\mathrm{N}=79$, frequencies total more than 100$)$

Three financial strategies had similar weighting. (a) More than two-thirds $(67 \%, \mathrm{n}=53)$ of respondents thought they would reap returns from their investments. Before retirement, they would have invested in shares (involving the global stock market), mutual funds, trading, and family investments. (b) Two thirds $(62 \%, \mathrm{n}=49$ ) would finance their retirement with pensions and end-of-service bonuses. (c) Two thirds $(61 \%, \mathrm{n}=48)$ said they would profit from their own enterprises or business projects or would engage in partnerships, self-employment, or expand into commercial activities (e.g., e-commerce) (see Figure 5).

To a much smaller extent, one-third $(32 \%, n=25)$ said they would finance their retirement using their own savings. Nine respondents $(11 \%)$ would profit from rent and leases from their own real estate. Ten percent $(\mathrm{n}=8)$ would rely on social security and returns from social insurance or state institutions. The Other category (14\%, $\mathrm{n}=11$ ) revealed alternative plans. Two respondents intended to create their own retirement plan. Two imagined borrowing small, easily repayable bank loans. Three said they would keep working beyond the national retirement age. Another three said they would obtain financial support from their adult children (see Figure 5).

\subsection{Question 6: Intent to Learn about Financial Literacy}

Virtually all (99\%) respondents said they planned to learn more about financial literacy and had suggestions for how the university could help (see Figure 6). Respondents were quite vocal about this issue. The majority (71\%, $\mathrm{n}=56$ ) recommended that the university provide a formal financial literacy course (free to all students) with suggestions for course offerings being available at the start of the year, end of the term, or in the final year. These courses could be some combination of online, short, intensive, specialized, or optional. A perusal of the data generated a roster of topics students thought should be included in the university's financial literacy course (see Table 1). 


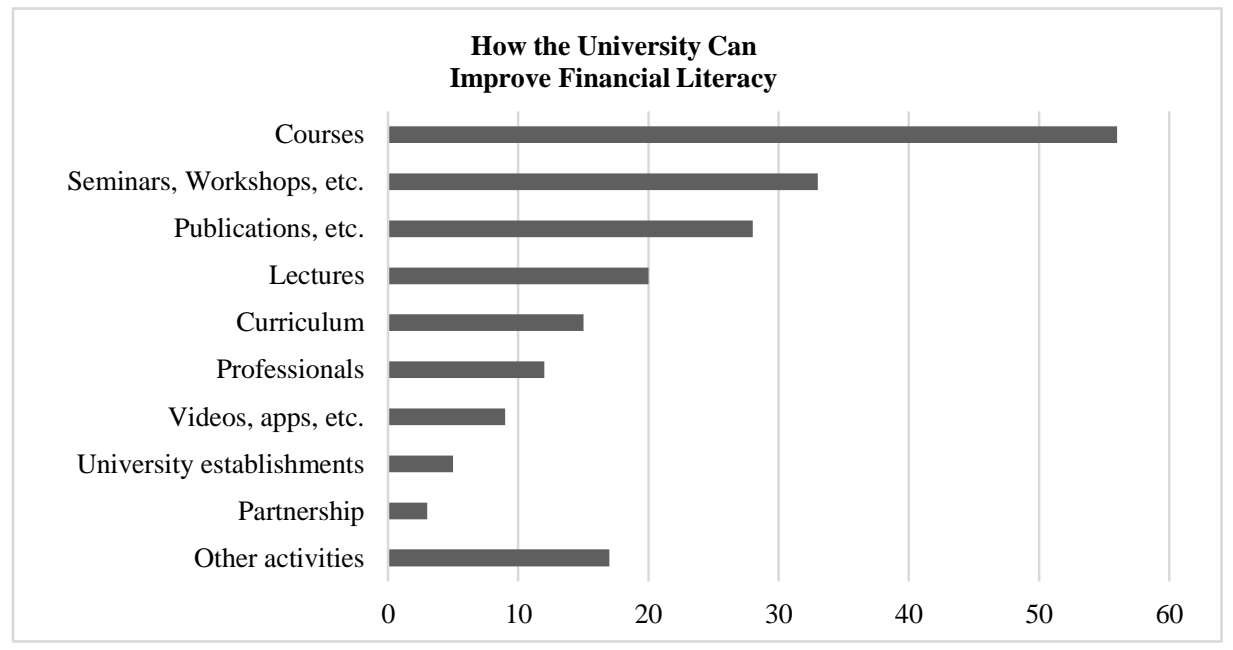

Figure 6. How the university can improve financial literacy ( $N=79$, frequencies total more than 100)

Table 1. Respondents' content suggestions for university's financial literacy curriculum

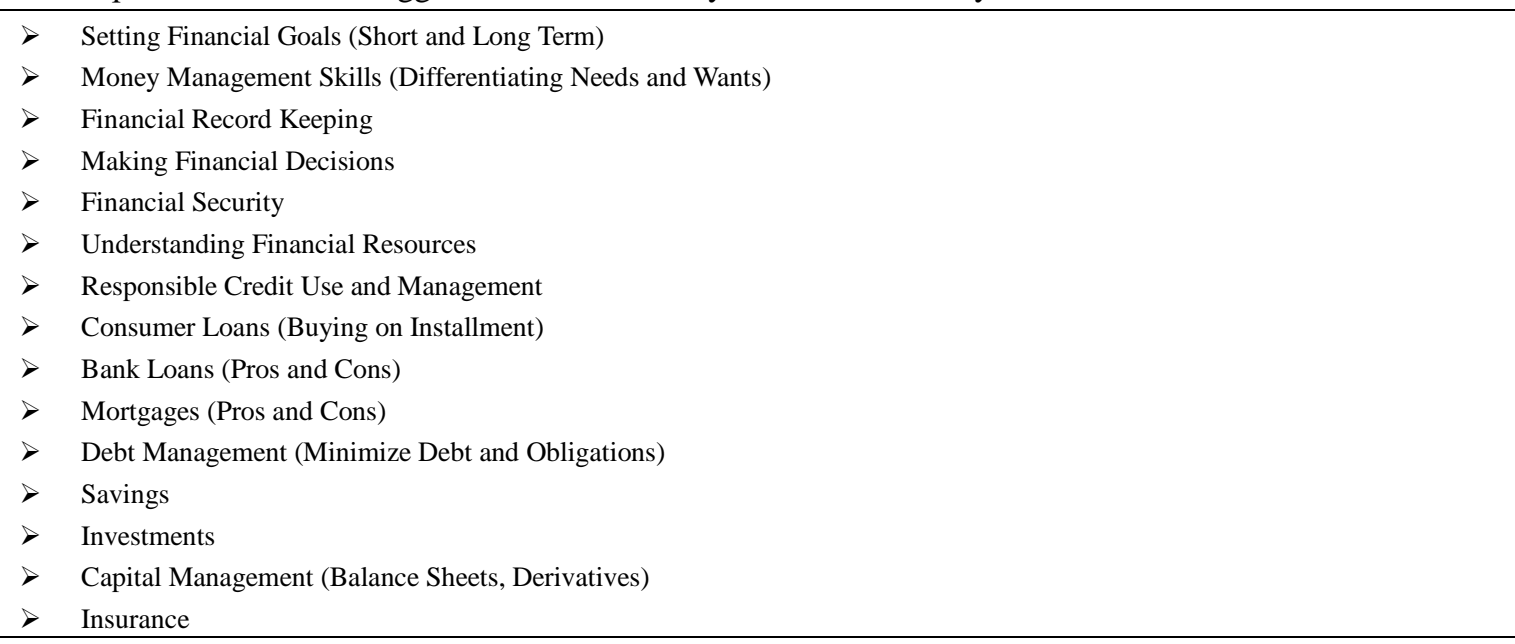

A fair number $(42 \%, n=33)$ of respondents also said that the university could tender informally disseminated financial literacy seminars, discussion forums, or training programs. About one-third (35\%) recommended awareness-raising initiatives wherein the university could make available financial literacy educational publications and show good practices. The former could be disseminated via a myriad of communication channels: emails, SMS (text messaging), social media (e.g., Twitter, Snapchat, and WhatsApp), brochures, flyers, posters, PowerPoints, books, research articles, and lecture series (see Figure 6).

One fifth (20\%) of respondents recommended their College of Economics and Administration as the ideal location for a financial literacy lecture series. More than one in ten $(15 \%)$ noted the importance of drawing on discussions with financial professionals, and $11 \%(\mathrm{n}=9)$ recommended educational videos, podcasts, and mobile applications to raise their peers' financial literacy. To a lesser but still important extent, some respondents $(\mathrm{n}=5)$ suggested setting up both a university student club to promote financial literacy and a student finance office to give advice on the matter. Also, the university could form a partnership with a body specializing in spreading financial awareness of financial literacy and stability $(n=3)$. In the Other category $(22 \%, n=17)$, several innovative ideas were tendered including but not limited to the university holding competitions on savings and investments and creating a webpage dedicated to financial literacy (see Figure 6).

\section{Discussion}

This study queried what are male Saudi university students' understandings of financial literacy and stability, and do they plan to achieve these and how? This inaugural male-focused study was inspired by Alghamdi and El-Hassan's (2020) earlier, as-yet-unpublished, work on the same topic just with mainly female respondents. Male students herein presented a clear set of understandings about financial literacy, which they valued, and they 
shared views on how to make this happen. The main takeaway is that while their understanding of what constitutes financial literacy was solid enough (with some gaps), their notion of how to ensure financial stability and financial security was in question. This impression is confounding because financial literacy should contribute to financial stability (McGregor, 2020; Singh, 2014).

To begin, respondents ironically placed little value on setting financial goals, having an emergency fund, or budgeting, which are considered the crux of any financial plan (Kenton, 2019; O'Connel, 2019; OECD, 2019). Strikingly, only $5 \%(\mathrm{n}=4)$ of respondents indicated the need to set aside money for an emergency fund, which is a cash reserve for unexpected life events, unplanned expenses, or financial exigencies (Consumer Financial Protection Bureau, n.d.). Also, while only one third said it was important to know about budgeting, more than half placed a high value on knowing about saving and investing. This result contradicts financial literacy theory, which proposes that controlling one's spending is imperative for saving and investing (Penn State University, 2021). People cannot save or invest what they do not have. The anticipated financial security of study respondents will be severely hampered if goal setting, budgeting skills, and emergency funds are not learned and used (Cautero, 2019; Howell et al., 2012).

In another irony, respondents self-rated as having good (47\%) to average (32\%) levels of financial literacy (totaling nearly $80 \%$ ). Good equates to satisfactory or decent, and average means typical or what is expected (Anderson, 2014). Their self-perception of satisfactory financial literacy is not fully reflected in the results, however. Respondents placed an inordinate weight on knowing about and engaging in investing $(75 \%)$ and entrepreneurship (49\%) instead of the more fundamental aspects of financial literacy: money, credit and debt management, insurance, estate planning, and taxes (Kenton, 2019; O'Connel, 2019). Privileging one financial strategy (e.g, investing) over their entire financial system sets up respondents for financial instability (Allen \& Wood, 2006).

To continue, this imbalanced understanding of financial literacy suggests that respondents will not be able to weather disturbances that threaten the ability of their financial system to absorb shocks (Lee et al., 2017; Schinasi, 2004). It seems that respondents were inherently risk takers (i.e., investment and entrepreneurship) with nominal respect for stability and security. Also, it takes a lot of confidence to actively embrace risky ventures in financial planning. Results initimate that respondents had a high sense of self-worth (i.e., accepting oneself), which impacts financial stability as does risk tolerance (Husiyah \& Fazilah, 2011).

Respondents also seemed to have an inordinate (perhaps misplaced) trust in other humans and institutions, which makes their financial stability more a game of chance than a calculated risk (Schinasi, 2004). Future research should strive to discern if respondents' intense focus on investments and entrepreneurship for earned and retirement living is widespread in the Saudi culture or whether this result reflects respondents' enrolment in an economic and administrative college focused on business and finance. Future scholarship should also focus on the subjective aspects of financial literacy (i.e., values, beliefs, attitudes, and self-perceptions) (Danes et al., 2013). Knowing how Saudi male university students understand financial literacy is just a start. Why this is the case is also important and merits further study.

Saudi male respondents' good self-rating for financial literacy contradicted Alghamdi and El-Hassan's (2020) finding that most female Saudi university students were not financially literate (60\% failure rate). The men self-rated (subjective), and the women were objectively tested. Attia and Engelhardt (2016) said Saudi men and women were on par in terms of being financially literate. One way to affirm or contradict this assertion is to arrange for our male respondents to complete Alghamdi and El-Hassan's (2020) instrument and then compare their objective empirical results with their subjective self-ratings herein. People's actual (objective) financial knowledge is important, because it can affect their subjective attitudes and financial behavior (OECD, 2018), which in turn can affect financial security and financial stability.

Saudi male respondents opined that, upon retirement, they would avail themselves of their investment income, pensions, end-of-service bonuses, or their own retirement savings. This study did not measure their degree of literacy about retirement per se. But relying on risky ventures like investing and building one's own savings for retirement seems imprudent (often requiring upwards of $\$ 500,000$ to a million dollars). Alghamdi and El-Hassan (2020) reported that female respondents underperformed in questions pertaining to Saudi retirement policy and retirement income sources. If one accepts Attia and Engelhardt's (2016) assertion that Saudi men and women are on par in terms of financially literacy, our results suggest that Saudi males may also lack comprehensive understandings of the Saudi retirement context. Saudi financial literacy initiatives should thus pay close attention to the retirement component of financial planning so that Saudi citizens can ensure stable and secure retirement finances vis-à-vis achieving Vision 2030. 
The OECD (2019, Chapter 5) conceptualized high school students' financial literacy as comprising four components: (a) money as a concept and money transactions (e.g., payment options, currencies, financial institutions, record keeping); (b) planning and managing finances (e.g., goal setting, prioritizing, income, budgeting, tracking expenses); (c) financial risk and reward (e.g., insurance, risk aversion and protection, investments, credit and borrowing); and (d) the financial landscape (e.g., consumer rights, law, and protection, sellers' integrity, economic climate) (see also Penn State University, 2021).

Positioning Table 1 generated by university students against a high school-focused approach (OECD, 2019), it is evident that, despite their maturity, university respondents herein did not fully understand that financial literacy pertains to (a) money as a concept and (b) the financial landscape. The former concerns being able to recognize, appreciate the purpose of, and know how to use different forms of money, access money, bank account reconciliation, payment options and retail transactions, interest, and comparison shopping. The financial landscape pertains to issues beyond the home that impact personal finances: economic climate, public policies, law and contract law, consumer protection legislation, marketplace rights and responsibilities of consumers and sellers, and protection of personal data (OECD, 2019).

Financial literacy entails being educated about money and finance as they are impacted both within and outside the home (O'Connel, 2019). Future research should explore male Saudi university students' appreciation for money and transactions and factors beyond the home that impact their financial security and stability. As changes in the economy, financial market, and employment market are inevitable, university students must ensure that their financial literacy knowledge is current (Douissa, 2020). The stability of their personal financial system to absorb shocks (major and mini) depends on this knowledge (Cautero, 2019; Schinasi, 2004) as does achieving Vision 2030.

On a final note, a person's financial system tends to have both strong and weak parts. Results indicate that respondents appeared knowledgeable about investing and starting a business or some other income-earning commercial enterprise but not so knowledgeable about goal setting, budgeting, and meeting emergencies. Schinasi (2004) explained that a personal financial system will remain stable if most parts are functioning within tolerable boundaries. But if the basics are not functioning well, the higher level strategies run the risk of failing therein compromising both stability (avoid collapse) and security (risk loss or damage) (Allen \& Wood, 2006). Results suggest that this scenario may well happen, which implies that Saudi male university students must learn to appreciate the merits of a well-balanced personal financial system that can withstand the vagaries of their own financial management and outside factors. Being literate in all aspects of finances is imperative.

\subsection{University Financial Literacy Course}

Financial literacy is currently not a mandatory university course in Saudi Arabia, but the majority (71\%) of respondents felt it should be. They were flexible about when this could be offered and in what format. They envisioned the course raising students' awareness of financial literacy thereby helping them gain financial security in the current times of instability and uncertainty. A small number of respondents $(11 \%, n=9)$ recommended using social media platforms to learn about financial literacy. Universities should consider this option. In combination with conventional teaching methods, technology might motivate students to take the first step in eliminating threats to their financial stability and achieving financial well-being and financial health (Children's Bureau, 2019) with both contributing to financial resilience in the face of unforeseen life events (Duncan \& Lo, 2018; Kagan, 2017).

Respondents tendered a roster of topics should the university decide to mount such a course (see Table 1). Upon analyzing this collection of financial literacy strategies, sometimes what is missing is as significant as what is present. Most of what conventionally constitutes financial literacy curricula (McGregor, 2020) was there. But there was no mention of retirement (although most questions alluded to retirement), taxation, or wills and estate planning, and the topic of insurance was limited to medical/health insurance (i.e., there was no mention of life, house, content, car, credit, or other forms of insurance).

Given their profound impact on a person's financial stability and security, it is imperative that university students gain an appreciation of the role that retirement, taxation, wills and estate planning, and insurance play vis-à-vis financial literacy. As a caveat, universities will have to determine this in the context of Saudi's culture. The SAMA values financial planning (KKF, 2018), which always concerns taxes, estate planning, insurance, and retirement planning (McGregor, 2020). SAMA's implicit endorsement of the need to understand these strategies strongly suggests that the latter are becoming part of the Saudi culture.

Respondents also had full intentions of focusing on salaries, return on investments (ROI), and their own enterprises as sustainable sources of both earnings and retirement income. This result means that any Saudi 
university financial literacy course should favor strategies for (a) career planning and securing long-term employment (i.e., employability and employment skills), (b) how to invest wisely and prudently and (c) how to start and run a business.

\subsection{Limitations}

This small-scale, exploratory investigation has limitations in sex (gender), scale, and study site. Future studies should include female respondents; gendered comparative analyses; larger samples from more universities; disciplines other than economics, business administration, and finance; and a full range of university levels (bachelor, graduate) and all years of study (foundation to senior). Demographic information should also be collected, because demographics can impact financial planning variables and strategies (Kask, 2003). Future studies should employ research designs seeking correlation, causation, or both.

\section{Conclusions}

This inaugural study of Saudi male university students' financial literacy revealed that, while their understanding of what constitutes financial literacy was solid enough (with some gaps), their notion of how to ensure financial stability and financial security was in question. Their self-rating for financial literacy (good to average) may have been unrealistic, because their perceived satisfactory financial literacy level was not fully reflected in the results. The KSA government is encouraged to pay special attention to secondary and university students' financial literacy acumen, because being literate in all manner of personal finances affects people's financial stability and financial security, which in turn feeds directly into the success of the national development plan (Vision 2030). A citizenry that is financially literate, stable, and secure will be better able to contribute to a healthy and thriving national economy.

Financial literacy is a burgeoning research theme around the world. This descriptive, exploratory study is significant for two reasons: it expanded personal financial literacy to include financial stability and financial security, and it tied these constructs to national development plans. Other Middle Eastern nations can draw lessons from the analysis herein. The results should also be of interest internationally for any nation intent on strengthening its economy through stronger household and individual finances via enhanced personal financial literacy.

\section{References}

Albassami, F., \& Alyousif, M. (2019). Measuring financial capability: The context of Saudi Arabia [Working paper WP/19/10]. Riyadh, Saudi Arabia: Saudi Arabian Monetary Authority.

Alghamdi, A. K. H., \& El-Hassan, W. S. (2020). Inaugural study of financial literacy of Saudi university students. Unpublished manuscript, Imam Abdulrahman bin Faisal University, Saudi Arabia.

Allen, W. A., \& Wood, G. (2006). Defining and achieving financial stability. Journal of Financial Stability, 2(2), 152-172. https://doi.org/10.1016/j.jfs.2005.10.001

Anderson, S. (ed.). (2014). Collins English dictionary (12th ed.). Glasgow, Scotland: Harper Collins.

Atkinson, A., \& Messy, F. (2012). Measuring financial literacy: Results of the OECD/ International Network on Financial Education (INFE) pilot study. Paris, France: OECD.

Attia, H., \& Engelhardt, H. (2016, December). Financial education initiatives in the Arab Region: A stocktaking report. Deutsche Gesellschaft für and Internationale Zusammenarbeit (GIZ) GmbH. Retrieved from https://www.amf.org.ae/sites/default/files/Studie_Arab.Region_190417_v5-FINAL.pdf

Cautero, R. (2019, April 8). What is financial security, and how do you get it? Retrieved from https://ca.finance.yahoo.com/news/financial-security-164248206.html

Children's Bureau. (2019, January 28). Benefits of being financially stable. Retrieved from https://www.all4kids.org/news/blog/benefits-of-being-financially-stable/

Consumer Financial Protection Bureau. (n.d.) An essential guide to building an emergency fund. Retrieved from https://www.consumerfinance.gov/start-small-save-up/start-saving/an-essential-guide-to-building-an-emerg ency-fund/

Danes, S. M., Rodriguez, M. C., \& Brewton, K. E. (2013). Learning context when studying financial planning in high schools: Nesting of student, teacher, and classroom characteristics. Journal of Financial Counseling and Planning, 24(2), 20-36.

Douissa, I. B. (2020). Factors affecting college students' multidimensional financial literacy in the Middle East. International Review of Economics Education, 35. https://doi.org/10.1016/j.iree.2019.100173 
Duncan, E., \& Lo, J. C. (2018). Financial wellbeing remains challenged in Canada: Highlights from the 2018 Financial Health Index study [White Paper]. Vancouver, BC: Seymour Consulting.

Emaikwu, S. O. (2011). Integrating entrepreneurship skills acquisition in the university curriculum for national development. Journal of Research in Education and Society, 2(3), 140-151.

Fareed, S. (2012, September 10). SEDCO launches Riyali financial literacy program. Saudi Gazette. Retrieved from https://johnhopebryant.com/2012/09/sedco-launches-riyali-financial-literacy-program.html

Harper, D. (2021). Online etymology dictionary. Retrieved from https://www.etymonline.com/

His Excellency the President of the University sponsors the opening of the workshop "Promoting a culture of savings in the Kingdom" with the participation of more than 20 economic institutions. (2019, February). King Abdulaziz University [Press Release]. Retrieved from https://www.kau.edu.sa/Content-0-AR-273820

Howell, R., Kurai, M., \& Tam, W. Y. L. (2012). Money buys financial security and psychological need satisfaction: Testing need theory in affluence. Social Indicators Research, 110(1), 17-29. https://doi.org/10.1007/s11205-010-9774-5

Husiyah, A. R., \& Fazilah, A. S. M. (2011). Factors contributing to financial stability of urban and rural families [Abstract]. Pertanika Journal of Social Sciences \& Humanities, 19(1), 99-112. $\quad$ Retrieved from http://psasir.upm.edu.my/id/eprint/40610

Kagan, J. (2017). Financial health. In C. Silver (Ed.), Investopedia online encyclopedia. Retrieved from https://www.investopedia.com/terms/f/financial-health.asp

Kask, J. (2003). Household debt and financial stability. Kroon and Economy, 4, 35-42.

Kenton, W. (2019). Financial literacy. In C. Silver (Ed.), Investopedia online encyclopedia. $\quad$ Retrieved $\quad$ from https://www.investopedia.com/terms/f/financial-literacy.asp

King Khalid Foundation. (2018). Financial inclusion in Saudi Arabia. Riyadh, Saudi Arabia: Author. Retrieved from https://kkf.org.sa/media/ipuh5olx/2-financial-inclusion-in-saudi-arabia-2018.pdf

Kingdom of Saudi Arabia. (2016). 2030 [Kingdom of Saudi Arabia Vision 2030]. Riyadh, Saudi Arabia. Retrieved from https://vision2030.gov.sa/sites/default/files/report/Saudi_Vision2030_EN_2017.pdf

Kingdom of Saudi Arabia. (2020, May). Financial Sector Development Program charter: Delivery plan 2020. Riyadh, Saudi Arabia. Retrieved from https://vision2030.gov.sa/sites/default/files/attachments/170719\%20FSDP\%20Program\%20Book\%2010\%2 0May\%202018\%20English\%20V3.pdf

Lee, S., Liu, M., \& Hu, M. (2017). Relationship between future time orientation and item nonresponse on subjective probability questions: A cross-cultural analysis. Journal of Cross-cultural Psychology, 48(5), 698-717. https://doi.org/10.1177/0022022117698572

Lindermann, N. (2019, August 8). What's the average survey response rate? [2019 Benchmark]. Retrieved from https://surveyanyplace.com/average-survey-response-rate/

Lusardi, A., Mitchell, O. S., \& Curto, V. (2010). Financial literacy among the young. Journal of Consumer Affairs, 44(2), 358-380. https://doi.org/10.1111/j.1745-6606.2010.01173.x

Lyons, A. C., \& Kass-Hanna, J. (2019) Financial inclusion, financial literacy and economically vulnerable populations in the Middle East and North Africa. Emerging Markets Finance and Trade, 1-40. https://doi.org/10.1080/1540496X.2019.1598370

Marra, R. M., \& Bogue, B. (2006, June 11-14). A critical assessment of online survey tools. Paper presented at Women in Engineering Programs and Advocates Network Conference. Pittsburg, PA. Retrieved from https://journals.psu.edu/wepan/article/view/58473/58161

McGregor, S. L. T. (2020). Tailoring bankruptcy insolvency education to ensure solvency literacy. Journal of Financial Counseling and Planning, 31(1), 55-68. https://doi.org/10.1891/JFCP-19-00018

Mian, T. S. (2014). Examining the level of financial literacy among Saudi investors and its impact on financial decisions. International Journal of Accounting and Financial Reporting, 4(2), 312-328. https://doi.org/10.5296/ijafr.v4i2.6487

Mistry, R. S., Biesanz, J. C., Taylor, L. C., Burchinal, M., \& Cox, M. J. (2004). Family income and its relation to preschool children's adjustment for families in the NICHD Study of Early Child Care. Developmental 
Psychology, 40(5), 727-745. https://doi.org/10.1037/0012-1649.40.5.727

Nidar, S. R., \& Bestari, S. (2012). Personal financial literacy among university students: A case study at Padjadjaran University, Bandung, Indonesia. World Journal of Social Sciences, 2(4), 162-171.

O'Connel, B. (2019, March 1). What is financial literacy and why does it matter to me? [Web log post]. Retrieved from https://pfeef.org/2019/03/01/what-is-financial-literacy-and-why-does-it-matter-to-me/

Organization for Economic Cooperation and Development. (2012). OECD INFE guidelines on financial education in schools. Paris, France: Author. Retrieved from https://www.oecd.org/daf/fin/financial-education/2012\%20Schools\%20Guidelines.pdf

Organization for Economic Cooperation and Development. (2018). PISA 2018 released financial literacy items. Paris, France. Retrieved from https://www.oecd.org/pisa/test/PISA2018-financial-literacy-items.pdf

Organization for Economic Cooperation and Development. (2019). PISA 2018 assessment and analytical framework. Paris, France. https://doi.org/10.1787/b25efab8-en

Penn State University. (2021). MoneyCounts: A Penn State financial literacy series. Retrieved from https://financialliteracy.psu.edu/moneycounts/

Ramshaw, A. (2016). The complete guide to acceptable survey response rates. Retrieved from https://www.genroe.com/blog/acceptable-survey-response-rate-2/11504

Saudi Gazette Report. (2020, January 26). Program launched to elevate financial literacy among primary school students. Saudi Gazette. Retrieved from https://saudigazette.com.sa/article/587640/SAUDI-ARABIA/Program-launched-to-elevate-financialliteracy -among-primary-school-students

Schinasi, G. J. (2004). Defining financial stability [IMF Working Paper No. 04/187]. Washington, DC: International Monetary Fund. https://doi.org/10.5089/9781451859546.001

Self-worth. (n.d.). In Merriam-Webster.com dictionary. Retrieved from https://www.merriam-webster.com/dictionary/self-worth

Singh, U. (2014). Financial literacy and financial stability are two aspects of efficient economy [Abstract]. Journal of Finance, Accounting \& Management, 5(2), 59-76.

US Department of the Treasury. (2008). 2008 annual report to the President of the President's Advisory Council on Financial Literacy. Washington, CD. Retrieved from https://www.treasury.gov/about/organizational-structure/offices/Domestic-Finance/Documents/PACFL_Dra ft-AR-0109.pdf

Western, B., Bloome, D., Sosnaud, B., \& Tach, L. (2012). Economic insecurity and social stratification. Annual Review of Sociology, 38, 341-359. https://doi.org/10.1146/annurev-soc-071811-145434

Why financial education is essential to Saudi Vision 2030. (2019, June 24). Albawaba. Retrieved from https://www.albawaba.com/business/why-financial-education-essential-saudi-vision-2030-1293143

\section{Copyrights}

Copyright for this article is retained by the author(s), with first publication rights granted to the journal.

This is an open-access article distributed under the terms and conditions of the Creative Commons Attribution license (http://creativecommons.org/licenses/by/4.0/). 